\title{
Strategi kampanye kreatif pengolahan sampah di permukiman padat penduduk
}

\author{
Aryo Bayu Wibisono*, Andhika Putra Perdana, Mike Nur Kartika Sari, Satriansyah \\ Akhlaqul Karima, Ahmad Ardanny Nanda Saputra, Ibrahnovan Suly Trizky Darma \\ Prodi Desain Komunikasi Visual, Fakultas Arsitektur dan Desain Universitas Pembangunan Nasional \\ Veteran Jawa Timur, Indonesia \\ Koresponden E-mail: aryobayuw.dkv@upnjatim.ac.id
}

(Diterima 23 Februari 2020|Disetujui 3 Juli 2020|Diterbitkan 30 Juli 2020)

\begin{abstract}
Cleanliness and waste management were common problems in city planning. The factors of the city's problems have been a varieticalistic discovery, ranging from flooding to a health factor from an unclean environment. The waste management in Surabaya is good enough but not all equally equal, especially in suburbs. This overcrowding undermines waste management, whereas Surabaya has already created a clear path to organizing the waste until mode of bus transportation that the payment based in exchange waste. It is considering it has not been able to enable people in suburbs to understand and implement the discipline on waste management. To bring the people in diciplines requires interesting methods, and motivate the people to do so. In the scholarly of design visual communication this method is called a social campaign, the objective in this research of this social campaign, to make the most nonessential organic and unorganic waste to be usefull. Data are taken from coastal area in Surabaya specifically in Tambak Wedi, Kenjeran. The population density and unclean enviroment in this area become a proper place to study. The methods used in this study are qualitative, with observational approaches to people, social experiment trials and socialization activities. This research is an applied public study, whose hope through this research that people are able to change their habits and understand about waste management
\end{abstract}

\section{Keywords: social campaign, surabaya city, waste management}

Permasalahan lingkungan merupakan isu global yang tidak bisa dihindari oleh kota di negara maju dan berkembang. Saat ini sampah merupakan masalah serius yang dapat mempengaruhi lingkungan, hal ini yang sering dihadapi oleh masyarakat kota di Indonesia pada umumnya. Setiap hari sampah dihasilkan dari sampah rumah tangga, baik itu sampah organik maupun sampah anorganik (Sukrorini et all, 2014). Sampah organik yaitu sampah yang dapat membusuk seperti sayuran, buah-buahan, sisa makan dan sebagainya. Sedangkan sampah anorganik yaitu sampah yang tidak dapat membusuk seperti botol plastik, kertas, kayu dan sebagainya.

Paragraf diatas sesuai dengan pendapat Andina dalam penelitiannya, 40\% sampah di Indonesia yang dihasilkan adalah dari rumah tangga, $20 \%$ dari pasar, $17 \%$ dari jalan raya, $9 \%$ sarana publik, $8 \%$ dari perkantoran dan $6 \%$ dari industri (Andina, 2019).

Dalam kasus kondisi lingkungan yang tidak sehat yaitu sampah yang ada di rumah tangga dapat menyebabkan berbagai macam penyakit, karena biasanya sampah rumah tangga dibuang begitu saja dengan memanfaatkan jasa perorangan dari tiap RW/RT kemudian dikirimkan ke Tempat Pembuangan Sampah Akhir (TPA). Masalahnya adalah sampah di TPA tersebut, kapasitasnya jauh melebihi kemampuan untuk dikelola, dan pola pengelolaan sampah di Indonesia masih open dumping (Prasetiwan, 2014). Pada tahun 2018 saja sebanyak 55,56 TPA di Indonesia melakukan operasi dengan open dumping, sedangkan 44,4\% melakukan dengan non open dumping (KLHK, 2019).
Sementara itu di Surabaya pada tahun 2017 mencatat $2.913,18$ ton sampah per hari, sedangkan pada tahun 2018 menurun menjadi 2.164,4 ton per hari (DKRTH, 2018). Data Sistem Informasi Pengelolan Sampah Nasional menjelaskan 1.477 ton sampah di kota Surabaya dikirim ke TPA Benowo, Surabaya. Sampah yang masuk ke TPA Benowo sebanyak $54,31 \%$ adalah sampah organik (Efendi, 2017).

Surabaya sendiri dikategorikan sebagai salah satu kota yang memproduksi sampah terbanyak di Indonesia bersama kota Makasar, Manado, Bandung dan Bekasi. Presentase sampah pada tahun 2017 - 2018 adalah sebagai berikut, Sisa makanan $54,31 \%$, Kayu ranting Daun 1,61\%, Kertas 14,63\%, Plastik 19,44\%, Logam 0,48\%, Kain Tekstil 1,47\%, Karet Kulit 2,33\%, Kaca 1,12\%, Lainnya 4,61\% (KLH 2019).

Permasalahan sampah ini seharusnya diseleseikan sejak dini, yakni pada level rumah tangga itu sendiri. Menurut O'Riordan manusia adalah makhluk yang memiliki nalar, jika ada informasi yang relevan terkait lingkungan tentunya akan merubah sikap dan prilakunya (Burn, 1991). Namun prilaku tersebut tidak cukup, perlu tindakan lebih di era sekarang, oleh karena itu harus disertai dengan aksi nyata untuk memilah sampah dan mendaur ulangnya (Zakianis \& Djaja, 2017). Sebenarnya polarisasi dan bentuk nyata dari kepedulian masyarakat di permukiman ini selaras dengan rencana Pemerintah Kota Surabaya, dengan menargetkan 6,56\% dalam pengelolaan kebersihan melibatkan masyarakat (Jayani, 2019). 
Atas dasar kasuistik terkait pemanfaatan sampah tersebut, penelitian ini mencari strategi yang relevan, yang dapat digunakan secara nyata dan kredibel untuk sampah rumah tangga. Tim peneliti melakukan studi kasus dan pengambilan sampel di wilayah Tambak Wedi, pesisir pantai Kota Surabaya. Hasil temuan dilapangan menemukan fakta, yakni banyak masyarakat yang belum peduli terhadap lingkungan. Selain itu, mereka belum bisa membedakan antara sampah organik dan sampah anorganik, yang merubah sampah tersebut sehingga dapat menguntungkan bagi masyarakat (Widyastutui, 2013). Menurut observasi tim peneliti di daerah Tambak Wedi, kota Surabaya sampah di campur dalam satu tong sampah, dan sampah banyak yang berserakan hingga ke selokan-selokan.

Dalam fenomena dan fakta yang di temukan diatas, menurut Roger dan Storey (Venus, 2004) perlu solusi yang taktis melalui strategi kampanye sosial yang berkala dan berkelanjutan. kampanye sosial ialah "serangkaian tindakan komunikasi yang terencana dengan tujuan untuk menciptakan efek tertentu pada sejumlah besar khalayak yang dilakukan secara berkelanjutan dan pada kurun waktu tertentu" (Venus, 2004). Menurut Charles U. Larson (1992) menjelaskan bahwa relevansi dari kampanye sosial adalah untuk menumbuhkan kesadaran masyarakat akan gejalagejala sosial yang sedang terjadi.

Oleh karena itu penelitian ini akan merancang terapan kampanye sosial, yang berlokasi di Kecamatan Tambak Wedi. Tujuan pembuatan kampanye sosial ini adalah untuk mengajak warga masyarakat untuk ikut melakukan terapan memilah sampah organik dan anorganik (Solicitor, 2019). Dalam rencana kegiatan kampanye sosial di kawasan pesisir Tambak Wedi Surabaya, akan merujuk pada tiga tahapan (Tjiptono dalam Tyas \& Soewardikoen, 2015), pertama Informing, memberikan tahapan informasi secara jelas terkait pesan yang ingin disampaikan. Kedua, Persuading, membujuk masyarakat untuk mengubah pandangan dan mendorong mereka agar aktif dalam kegiatan kampanye sosial. Ketiga, Reminding, mengingatkan target dan pesan yang telah dilaksanakan sebelumnya.

Pelaksanaan proses kampanye ini dilakukan selama tiga bulan. Pelaksanaan tersebut melingkupi observasi lapangan, menemukan fakta lapangan, wawancara pada ketua RW juga beberapa warga sekitar Tambak Wedi, pembuatan sosial eksperimen, penyuluhan kampanye sosial tentang sampah dan evaluasi terhadap efektifitas kampanye sosial yang sudah dilaksanakan.

\section{BAHAN DAN METODE}

Dalam penelitian berbasis perancangan kampanye sosial ini menerapkan metode melalui 5 tahapan, yakni identifikasi, legitimasi, partisipasi, penetrasi dan distribusi (Larson, 1992) dan model ini dianggap paling populer di berbagai belahan dunia (Venus, 2004). Oleh karena itu metodologi dalam kampanye lingkungan ini antara lain, (1) Melaksanakan observasi lapangan untuk mencari lokasi yang tepat untuk kami adakan penyuluhan kampanye sosial sampah. (2) Menemukan fakta lapangan untuk menentukan sebuah strategi pemecahan masalah yang tepat pada masyarakat Tambak Wedi. (3) Wawancara pada ketua RW juga beberapa warga sekitar Tambak Wedi tentang sampah, untuk memperkuat temuan fakta yang telah ditemukan sebelumnya. (4) Membuat sosial eksperimen untuk menguji tingkat pemahaman masyarkat Tambak Wedi akan sampah. (5) Penyuluhan kampanye sosial untuk memberikan penyuluhan tentang pengolahan sampah organik dan anorganik untuk dijadikan sesuatu yang lebih menguntungkan. (6) Evaluasi untuk mengukur tingkat keberhasilan dan efektifitas kampanye yang sudah kami laksanakan dengan mengunjungi rumahrumah warga dan mengecek sampah warga Tambak Wedi apakah sudah terpilah dengan baik.

Untuk mencapai tujuan dari kampanye sosial ini, dibutuhkan perancangan strategi kampanye dengan mengetahui target yang dituju secara jelas sehingga perlu menentukan target segementasi audiens (Karatajaya, 2006). Adapun target audiens yang telah ditentukan sebagai berikut:

\section{Demografis}

$\begin{array}{ll}\text { Jenis Kelamin } & \text { : Pria dan wanita } \\ \text { Usia } & : 30-50 \text { tahun } \\ \text { Pendidikan } & \text { : SMA } \\ \text { Kelas sosial : Menengah Kebawah }\end{array}$

\section{Geografis}

RW 02, Kelurahan Tambak Wedi, Kecamatan Kenjeran, Kota Surabaya, Jawa Timur, Indonesia

\section{Psikografis}

Masyarakat yang belum dapat mengelolah dan memilah sampah organik dan anorganik di RW 02 Tambak Wedi, Kelurahan Kenjeran dan sekitarnya.

\section{Behavior}

Masyarakat yang belum memiliki pengetahuan yang benar tentang cara pengolahan dan pemanfaatan. 


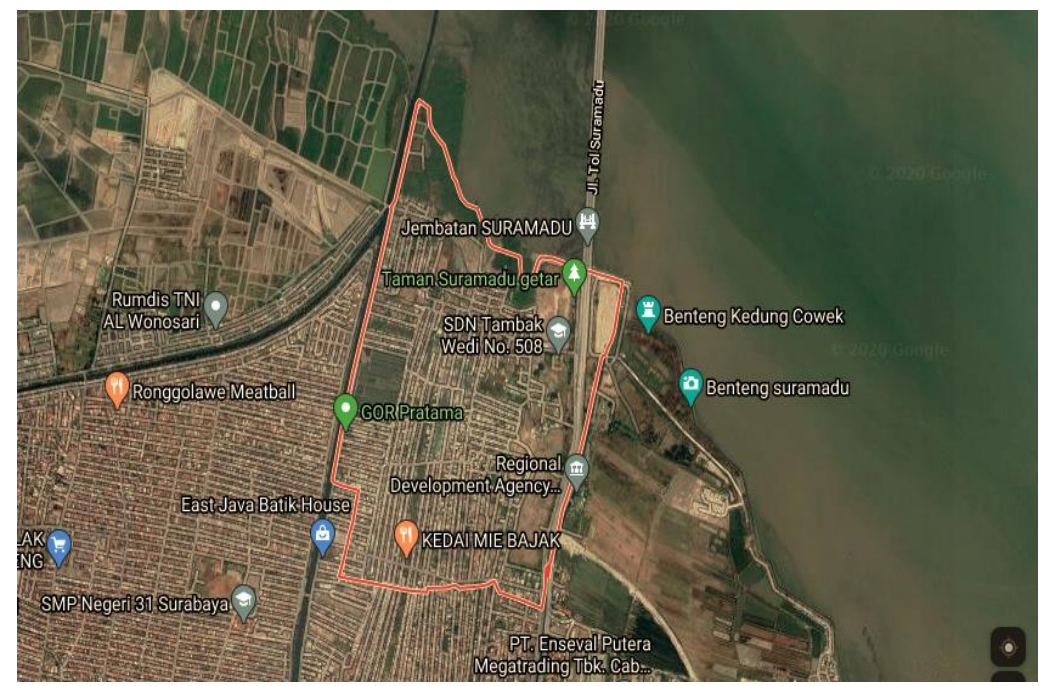

Gambar 1. Wilayah Kecamatan Tambak Wedi di Pesisir Kenjeran, kota Surabaya
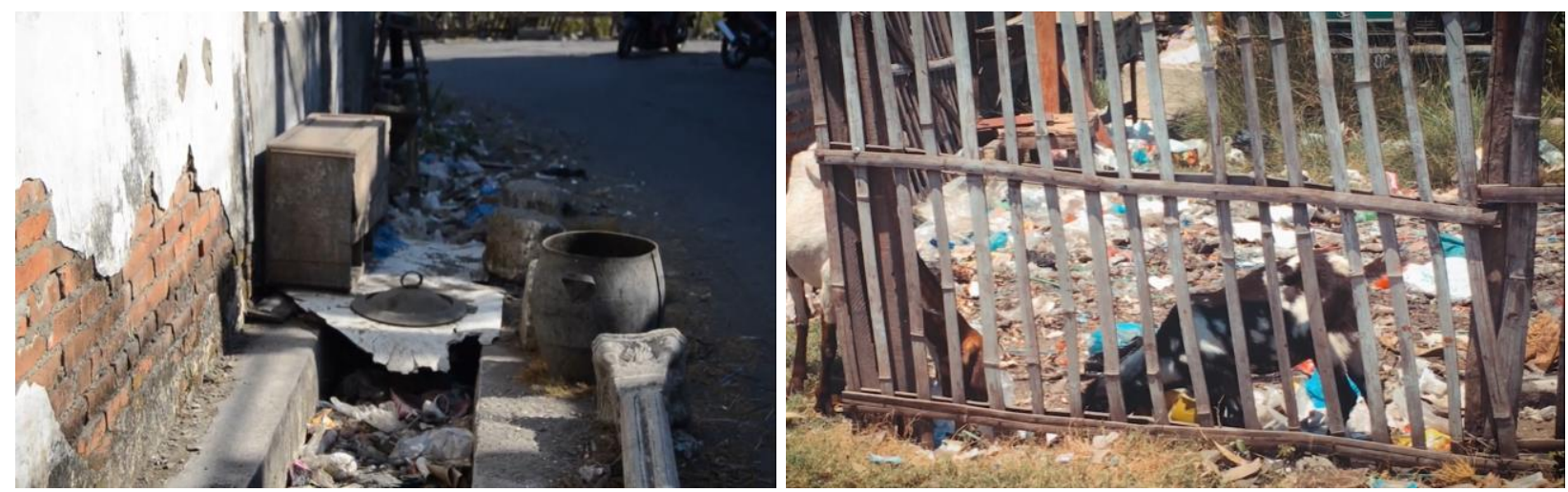

Gambar 2. Sampah di Kecamatan Tambak Wedi, kota Surabaya.

\section{HASIL DAN PEMBAHASAN}

Permukiman di Kecamatan Tambak Wedi kota Surabaya menurut hasil observasi dilapangan, memiliki daerah yang padat penduduk. Merujuk pada wawancara dan temuan dilapangan melalui video eksperimen,(https://www.youtube.com/watch?v=iz3

CZgam914), masyarakat Tambak Wedi berkesimpulan, tidak memiliki pengetahuan dengan tidak memilah sampah dan memanfaatkannya, faktornya antara lain lingkungan yang penuh sampah dianggap biasa oleh kalangan masyarakat, pengelolaan sampah dianggap sebagai sesuatu hal yang kotor, dan tidak menyenangkan untuk dikelola.

Kemudian yang terakhir adalah ketidaktahuan atas skema yang tepat, tentang model pemanfaatan sampah yang dapat mendukung transportasi yang sedang dicanangkan oleh kota Surabaya dengan menukarkannya di Bank Sampah. Hal ini sebenarnya akan mampu menambah kas kampung, untuk mengembangkan wilayah dan menambah kesejahteraan masyarakat (Dirgantara, 2013).

\section{Keyword Kampanye Sosial}

Dalam penelitian kampanye sosial, sebelum muncul strategi kampanye sosial yang tepat, terlebih dahulu memunculkan keyword. Fungsi dan tujuan dari keyword ini adalah untuk membuat kesepakatan dan koridor penelitian terkait visual kampanye sosial dan strategi komunikasinya (Yeo, 2013).

Keyword yang tepat untuk penelitian kampanye sosial ini adalah "Sampah dan Untung" representasi sampah dan untung adalah berdasarkan dari faktor sampah di lingkungan Tambak Wedi serta pola pemanfaannya kedepan. Keyword yang muncul lantas dirancang secara strategis keterkaitannya dengan konsep verbal dan konsep visual. Pada konsep verbal akan berbentuk "tagline" atau teks, sedangkan konsep visual berbasis image atau gambar (Moriarty, 2011). Konsep verbal "tagline" berasal dari 3 suku kata, "sampah, bawa, dan untung" yang disingkat menjadi "SAMBUNG" kependekan dari "Sampah Bawa Untung"

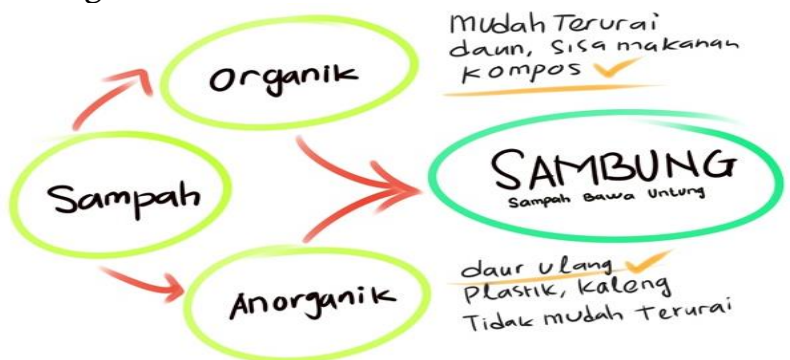

Gambar 3. Kemunculan Ide "SAMBUNG"

Pada konsep visual dari keyword kemudian dikembangkan menjadi visual kampanye sosial, salah 
satunya logo pada kampanye sosial (Gorranson \& Fagerholm, 2018). Logo yang dibuat bertujuan sebagai identitas penelitian kampanye sosial. Logo yang dirancang kemudian disesuaikan dengan kata - kata SAMBUNG. Singkatnya logo penelitian kampanye sosial ini bertujuan agar warga mudah untuk mengingat dan mengenali penelitian kampanye sosial, yang diterapkan dilapangan. Konotasi warna yang digunakan adalah warna hijau dan kuning yang merepresentasikan sampah organik dan anorganik (Amsteus, et.all, 2015).
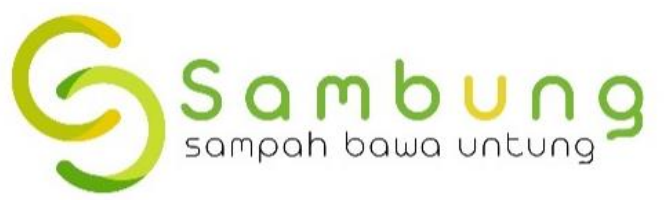

Gambar 4. Logo SAMBUNG

\section{Media Kampanye Sosial}

Penyampaian pesan dalam kampanye sosial haruslah memiliki media yang efektif dan efisien, selain itu media harus tepat guna agar komunikasi dapat tersampaikan (Bauman et all, 2018). Menurut Lane dan King (2011), untuk menyampaikan pesan diperlukan media dengan tampilan visual, keselarasan gaya, dan rasa yang konsisten pada media tersebut. Media yang diterapkan adalah penunjang program kampanye, dengan tujuan sebagai sarana untuk menyampaikan edukasi kepada audiens tentang Pengolahan dan Pemilahan Sampah. Media yang dipilih dalam kampanye sosial ini adalah media yang disesuaikan dengan sasaran atau target audiens kampanye sosial dalam penelitian ini, yakni masyarakat Tambak Wedi Surabaya. Media tersebut antara lain yaitu :

\section{Tempat Sampah Portable}

Tempat sampah dalam kampanye sosial ini digunakan sebagai media pemilahan sampah organik dan anorganik. Bentuk sampah ini dirancang dengan bentuk yang ringkas dan portable, agar efektif dan mudah diletakkan dimana saja karena tidak membutuhkan ruang yang besar. Selain itu dapat mengatasi pola membuang sampah secara langsung, sebelum di pilah, yakni langsung di ikat pada plastik hitam besar. Bahan utama yang digunakan adalah kayu "jenis reng" yang memiliki harga yang terjangkau dan mudah dibentuk. Bentuk tempat sampah portable sendiri dikategorikan sebagai ambience media dalam kampanye sosial ini, tujuan nya agar pesan kampanye yakni "Sampah Bawa Untung" dapat memiliki keterkaitan dengan penelitian ke masyarakat (Rosengren, Modig, \& Dahlen, 2018)

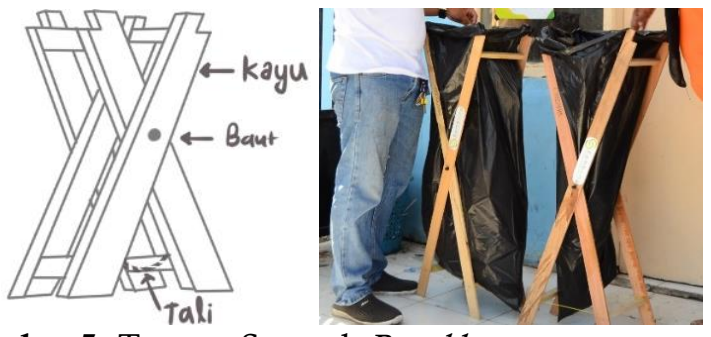

Gambar 5. Tempat Sampah Portable

\section{Poster}

Poster didesain serupa dengan warna logo yaitu warna hijau dan kuning. Tujuan pembuatan poster ini untuk memberikan informasi kepada masyarakat agar mengikuti kampanye sosial yang akan dilaksanakan di daerah Tambak Wedi selama beberapa bulan (Wakefield, et.all, 2010). Penempatan dari poster ini adalah pada papan pengumuman yang ada di kampung, dan di warung yang terletak di sekitar Tambak Wedi.

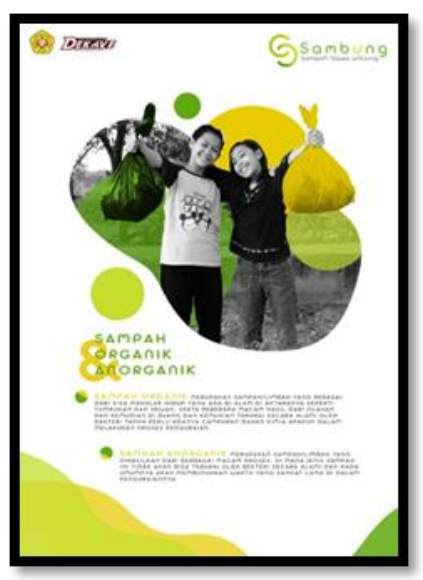

Gambar 6. Poster Kampanye

\section{Backdrop}

Backdrop yang dirancang bertujuan untuk background sewaktu sosialisasi dan seminar di Tambak Wedi. Backdrop ini berguna secara multifungsi, selain sebagai background pada sosialisasi, media backdrop juga berguna untuk informasi dan sosialisasi secara umum di masyarakat Tambak Wedi terkait kampanye sosial yang akan direncanakan.

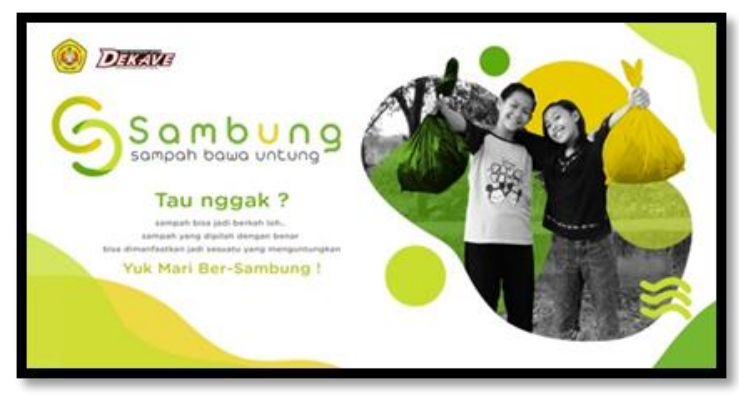

Gambar 7. Backdrop Kampanye Sosial 


\section{Pin dan T-Shirt}

Pin yang didesain bertujuan untuk menunjukan identitas pelaku dan peserta, bagi warga yang mengikuti kampanye sosial yang akan dilaksanakan.

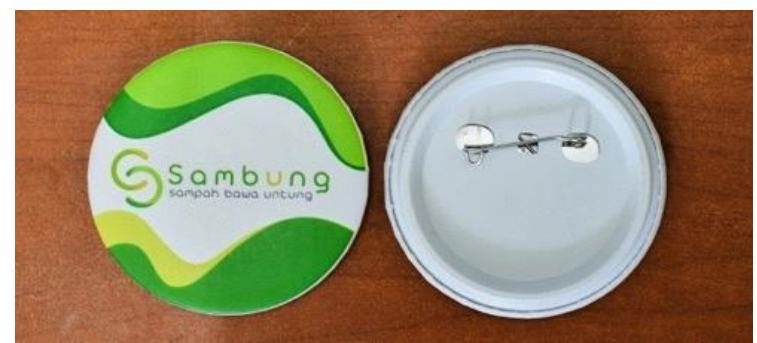

Gambar 8. Pin Kampanye Sosial

Sedangkan media T-Shirt atau kaos pada kampanye sosial bertujuan membentuk identitas bagi panitia yang melaksanakan kegiatan kampanye sosial dilapangan.

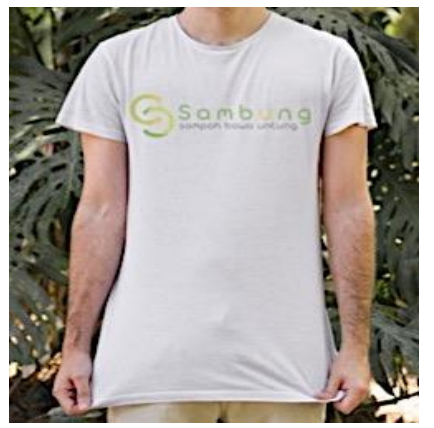

Gambar 9. Kaos identitas Kampanye Sosial

\section{Video}

Video kampanye sosial ini dibuat untuk menunjukan dan dokumentasi hasil daripada Kampanye Sosial yang di laksanakan di Tambak Wedi. Video ini dapat dilihat di link Youtube sebagai berikut,(https://www.youtube.com/watch?v=EYq148 VGHvw). Video hasil ini akan diupload ke Youtube, sebagai tujuan untuk pembelajaran dan contoh oleh masyarakat di wilayah Tambak Wedi Surabaya. Pendapat ini didukung oleh Krisnhan \& Sitaraman, yang menjelaskan jika video berbasis online dapat menjadi sisi persuasif, hal ini tentunya sangat bermanfaat jika dalam penelitian kampanye sosial ini (2013).

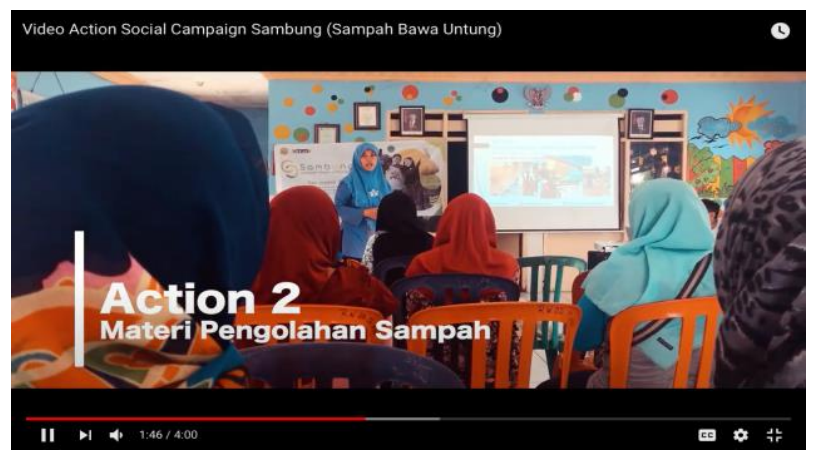

Gambar 10. Video Kegiatan Kampanye Sosial

\section{Strategi Kampanye}

Strategi kampanye sosial ini didasari dari ideologically or Cause Oriented Campaigns, yakni melaksanakan kampanye sosial berdasarkan dari isu perubahan sosial (Venus, 2004). Dari ideologically or Cause Oriented Campaigns tersebut muncul tiga langkah strategis dari aspek penting kampanye sosial, yang digagas di Tambak Wedi Surabaya. Tiga langkah tersebut yakni informing, persuading, dan reminding (Tjiptono, 2008).

Strategi pertama (1) dalam kampanye sosial ini adalah mengedepankan aspek Informing sebagai PreAction. Yakni melalui langkah penyuluhan kampanye, tentang pengolahan sampah organik dan anorganik. Dalam penyuluhan ini peneliti bekerja sama dengan pihak Dinas Kebersihan dan Ruang Terbuka Hijau (DKRTH) dan Bank Sampah Induk (BSI) sebagai narasumber. Materi pemilahan sampah organik oleh pihak DKRTH menunjukan cara yang dapat di gunakan pada area permukiman melalui penanaman menggunakan pot. Sedangkan materi pemilahan sampah anorganik disampaikan oleh BSI. Selain itu BSI juga menyampaikan urgensi, dan pentingnya menukarkan sampah dalam hal menambah kesejahteraan masyarakat, atau wilayah RW atau RT.

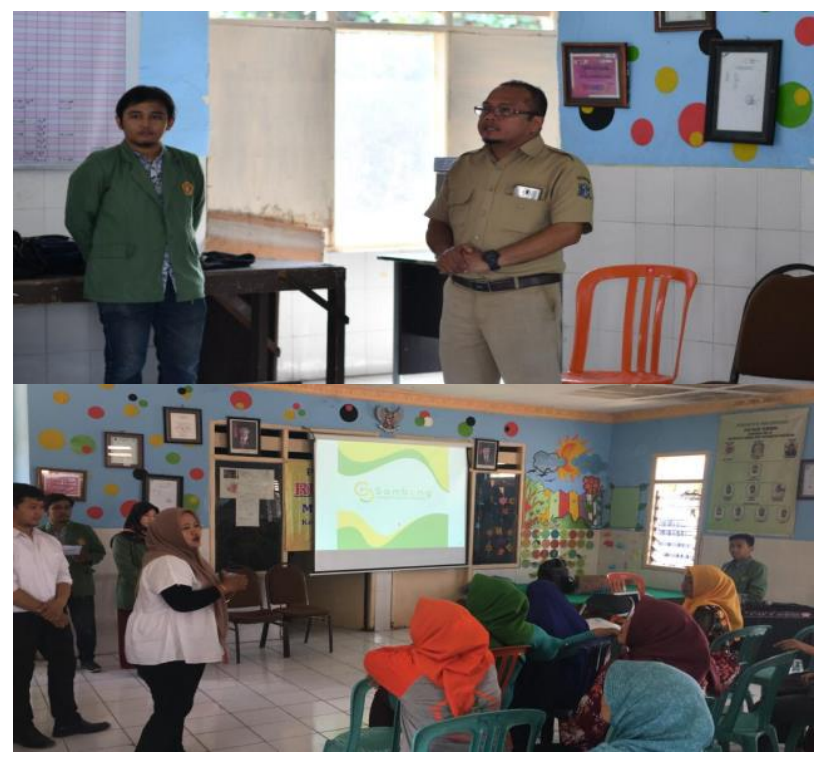

Gambar 11. Sosialisasi dan Penyuluhan Oleh Dinas Kebersihan dan Ruang Terbuka Hijau (DRKTH) dan Bank Sampah Induk (BSI)

Strategi kedua (2) adalah persuading sebagai action campaigns. Strateginya adalah melakukan aksi pembuatan biopori untuk tanaman, bersama - sama dengan masyarakat Tambak Wedi. Biopori dibuat menggunakan bahan daur ulang pipa PVC yang dilubangi dibagian bawahnya secara sejajar dengan jarak tertentu sebagai lubang resapan bagi akar tanaman untuk mencapai pupuk dan kemudian diaplikasikan di dalam pot tanpa memerlukan ruang yang besar. Biopori dibuat untuk mengurangi produksi sampah organik rumah tangga dan membuatnya menjadi pupuk kompos dengan cara memasukkan 
sampah organik tersebut ke dalam lubang pipa PVC. Selanjutnya, pengenalan media tempat sampah yang telah didesain secara efektif untuk memilah sampah organik dan anorganik agar mudah diolah (Mirawati \& Winarsih, 2019).

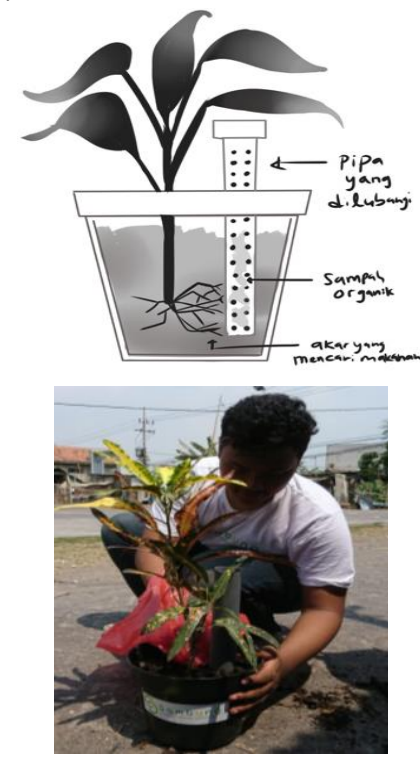

Gambar 12. Cara Penanaman dan Foto Kegiatan Pada Lapangan

Strategi yang terakhir (3) adalah reminding sebagai langkah Pra-Action. Strategi yang dibuat adalah melakukan evaluasi kepada warga dengan mengecek pemilahan sampah yang ada dalam rumah warga, apakah langkah yang dilakukan sudah sesuai dengan rencana dan instruksi awal. Evaluasi ini perlu untuk mengukur tingkat efektifitas pada kampanye sosial yang dilaksanakan.

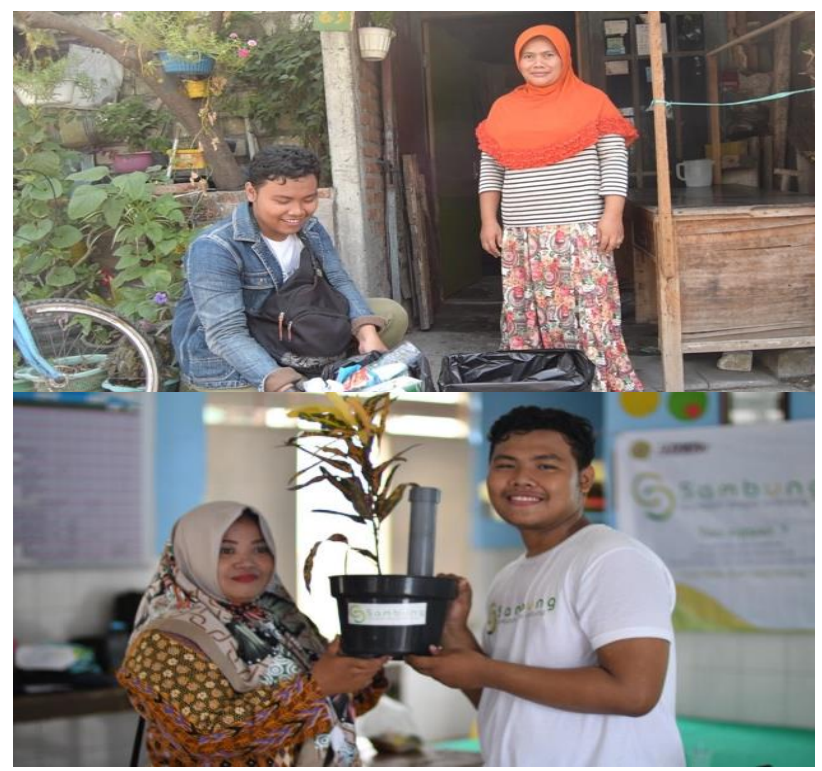

Gambar 13. Evaluasi dan Pengukuran Hasil penanaman Biopori

\section{SIMPULAN}

Pada strategi kampanye sosial dibutuhkan cara yang efektif untuk dapat menyeleseikan permasalahan sampah di level permukiman atau perkampungan. Langkah kampanye sosial dibuat, tidak saja melalui cara dengan pendekatan verbal saja, namun juga melalui strategi visual yang komprehensif. Yakni melalui cara strategi yang tepat pengolahan sampah secara bersama secara organik dan anorganik, pada kawasan pesisir Tambak Wedi kota Surabaya.

Karakteristik masyarakat dari Kecamatan Tambak Wedi kota Surabaya memiliki sifat konservatif dan tergolong permukiman kumuh, perlu tahapan yang menarik dan lebih menekankan rekonsiliasi terlebih dahulu dengan pihak terkait (RT, RW, Preman kampung dan Ibu rumah tangga) ketika akan melakukan kampanye sosial.

Faktor lain dalam penelitian ini agar kampanye berhasil, strategi kampanye sosial yang dirancang ke Kecamatan Tambak Wedi, Surabaya menekankan pada faktor edukasi yang hasilnya akan dilihat secara langsung oleh masyarakat. Faktor ini penting dalam tipologi karakter masyarakat yang konservatif dan memiliki lingkungan kumuh, karena membangun kedekatan secara komunikatif yang informal, membangun kepercayaan sektor masyarakat di pemukiman.

\section{UCAPAN TERIMA KASIH}

Dalam hal ini peneliti banyak mengucapkan terimakasih kepada Ketua RW 2 Kelurahan Tambak Wedi dan juga para warganya yang sangat antusias mengikuti agenda kampanye sambung hingga selesai. Tidak lupa penulis ucapkan terimakasih kepada Dinas Kebersihan dan Ruang Terbuka Hijau (DKRTH) Kota Surabaya dan juga Bank Sampah Indonesia (BSI) Kota Surabaya yang telah banyak membantu untuk memberikan materi dan sosialisasi terkait dengan pengelolaan sampah yang baik.

\section{DAFTAR PUSTAKA}

Amsteus, M., Al-Shaaban, S., Wallin, E., \& Sjöqvist, S. (2015). Colors in Marketing : A Study of Color Associations and Context (in) Dependence. The International Journal of Academic Research in Business and Social Sciences, 6, 32-45.

Andina, Elga. (2019). Analisis Perilaku Pemilahan Sampah di Kota Surabaya.

https://doi.org/10.22212/aspirasi.v10i2.1424

Burn, S. M. (1991). Social Psychology and the Stimulation of Recycling Behaviors: The Block Leader Approach. Journal of Applied Psychology, 21(8), 611-629. doi: 10.1111/j.1559-1816.1991. tb00539.x

Baum, D., Spann M., Fuller J., \& Thurridl, Carina (2018) Journal of Retailing and Consumer Services. https ://doi.org/10.1016/j.jretconser.2018.07.003

Chaer, Abdul \& Agustina, Leonie. 2004. Sosiolinguistik Perkenalan Awal. Edisi Revisi. PT. Rineka Cipta, Jakarta.

Dinas Kebersihan dan Ruang Terbuka Hijau Kota Surabaya. (2018). Profill Dinas Kebersihan dan 
Ruang Terbuka Hijau Kota Surabaya Tahun 2018. Surabaya: Dinas Kebersihan dan Ruang Terbuka Hijau Kota Surabaya.

Dirgantara, I. M. (2013). Pengetahuan Mendaur Ulang Sampah Rumah Tangga Dan Niat Mendaur Ulang Sampah. doi: https://doi.org/10.14710/jsmo.v10i1.5572

Efendi, Z. (2017). Ini Solusi Pemkot Surabaya Kurangi Sampah Masuk ke TPA dan Pantai. Retrieved from https://m.detik.com/news/ berita-jawa-timur/d3433330/ini-solusi-pemkot-surabaya-kurangisampah-masuk-ke-tpa-dan-pantai. on 18 November 2019.

Gorranson, K., \& Fagerholm, A. (2018), "Towards visual strategic communications : An innovative interdisciplinary perspective on visual dimensions within the strategic communications field", Journal of Communication Management, Vol. 22 No. 1. https://doi.org/10.1108/JCOM-12-2016-0098

Jayani, D.H. (2019). Menengok Pengelolaan Sampah di Jakarta dan Surabaya. Retrieved from https://katadata.co.id/berita/2019/08/03/ menengok-pengelolaan-sampah-di-jakarta-dansurabaya, on 11 September 2019.

Kartajaya, Hermawan. 2006. Elemen Marketing on Segmentation, Mizan, Bandung.

Kementerian Lingkungan Hidup dan Kehutanan. Data Umum Sistem Pengelolaan Sampah Nasional. Retrieved from : http://sipsn.menlhk.go.id/?q=3adata-

umum\&field_f_wilayah_tid=1519\&field_kat_kota_ tid=All\&field_periode_id_tid=2168, on 11 September 2019.

Krishnan, S. S., \& Sitaraman, R. K. (2013). Understanding The Effectiveness Of Video Ads. Proceedings of the 2013 Conference on Internet Measurement Conference - IMC 13 doi:10.1145/2504730.2504748

Lane, W. Ronald. \& King, Karen. (2011). Klappner's Advertising Procedure. Prentice Hall Press, New Jersey.

Larson, Charles U. (1992). Persuasion; Reception and Responsbility. Wardsworth Publishing Company, California, USA.

Mirawati, A., \& Winarsih. (2019). Kualitas Kompos Berbahan Dasar Sampah Rumah Tangga, Sampah Kulit Buah, dan Sampah Daun dalam Lubang Resapan. https://jurnalmahasiswa.unesa.ac.id/index.php/le nterabio/article/view/30641/27905

Muhammad, B., Arifianto \& Sulistyarso, Haryo (2016). Arahan Penataan Lingkungan Permukiman Kumuh Kecamatan Kenjeran Dengan Pendekatan Eco-Settlements. JURNAL TEKNIK ITS Vol. 5, No. 2.

Moriarty, Sundra. Nancy Mitchell, William Wells. (2011). Advertising (edisi ke delapan). Jakarta: Kencana.

Prasetiawan, T. (2014). Peluang Implementasi Extended Producer Responsibility (EPR) di Indonesia, dalam Nurhayati (Ed.), Sampah:
Permasalahan dan Pengelolaannya. Jakarta: P3DI Setjen DPR RI dan Azza Gra ka.

Penebar Swadaya. (2008). Penanganan dan Pengelolaan Sampah. Jakarta : Penebar Swadaya.

Rosengren, S., Modig, E., \& Dahlén, M. (2014). The value of ambient communication from a consumer perspective. Journal of Marketing

Communications, 21(1), 20-

32.doi:10.1080/13527266.2014.970825

Sukrorini, Tri., Budiastuti, S., Ramelan A. Handono \& Kafiar F. Pither (2014). Kajian Dampak Timbunan Sampah Terhadap Lingkungan Di Tempat Pembuangan Akhir (TPA) Putri Cempo Surakarta. Jurnal EKOSAINS | Vol. 6 | No. 3.

Solicitor C.R.E.C, A., Putra, D., Huwaidaa Hapsari, R., Dewi, M., Rahmanzah, G., Adiguna P, A., \& Fathqurrahman J, F. (2019). Kampanye Sosial Memilah dan Mengolah Sampah Organik maupun Anorganik di Dusun Pucukan. https://doi.org/10.31091/sw.v7i1.680

Tjiptono, F. (2008). Strategi Bisnis Pemasaran. Penerbit: Andi, Yogyakarta.

Tyas, Oktavian E. W \& Soewardikoen, Didit W. (2015). Social Campaign Media Design of Books For Papua. Jurnal Komunikasi Visual \& Multimedia. Vol. 7 No. 1 Tahun 2015. http://journals.itb.ac.id/index.php/wimba/article /view/10796/3982

Venus, A. (2004). Manajemen Kampanye. Penerbit : Simbiosa Rakatama Media, Bandung.

Widyastutui, S. (2013). Perbandingan Jenis Sampah Terhadap Lama Waktu Pengomposan Dalam Lubang Resapan Biopori. Teknik WAKTU Volume 11 Nomor 01 - Januari 2013.

Yeo, J. P.-H. (2013). An overview of research methods in visual communication design education. International Journal of Design Creativity and Innovation, 2(1), 51-62. doi: $10.1080 / 21650349.2013 .794720$

Yuliawati, \& Enjang P. I. (2018). identifikasi kampanye gerakan lingkungan hijau dalam mendukung ketahanan pangan nasional: (Studi Kasus Tentang Identifikasi Kampanye Progam Lingkungan Hijau Melalui Tanaman Hidroponik Oleh Kodim 0503 Jakarta Barat). Jurnal Politikom Indonesiana, Vol. 3. No. 01

Wakefield, M. A., Loken, B., \& Hornik, R. C. (2010). Use Of Mass Media Campaigns To Change Health Behaviour. The Lancet, 376(9748), 1261-1271. doi:10.1016/s0140-6736(10)60809-4

Zakianis, S., \& Djaja, I. M. (2017). The Importance of Waste Management Knowledge to Encourage Household Waste-Sorting Behaviour in Indonesia. International Journal of Waste Resources, 07(04). doi: 10.4172/2252-5211.1000309. 